\title{
Craniosynostosis: prenatal diagnosis by 2D/3D ultrasound, magnetic resonance imaging and computed tomography.
}

\author{
Talita Micheletti Helfer ${ }^{1}$, Alberto Borges Peixoto', Gabriele Tonni', Edward Araujo Júnior1 ${ }^{*}$
}

${ }^{1}$ Department of Obstetrics, Paulista School of Medicine - Federal University of São Paulo, São Paulo-SP, Brazil, ${ }^{2}$ Department of Obstetrics and Gynecology, Guastalla Civil Hospital, AUSL Reggio Emilia, Italy

\begin{abstract}
Craniosynostosis is defined as the process of premature fusion of one or more of the cranial sutures. It is a common condition that occurs in about 1 to 2,000 live births. Craniosynostosis may be classified in primary or secondary. It is also classified as nonsyndromic or syndromic. According to suture commitment, craniosynostosis may affect a single suture or multiple sutures. There is a wide range of syndromes involving craniosynostosis and the most common are Apert, Pffeifer, Crouzon, Shaethre-Chotzen and Muenke syndromes. The underlying etiology of nonsyndromic craniosynostosis is unknown. Mutations in the fibroblast growth factor (FGF) signalling pathway play a crucial role in the etiology of craniosynostosis syndromes. Prenatal ultrasound's detection rate of craniosynostosis is low. Nowadays, different methods can be applied for prenatal diagnosis of craniosynostosis, such as two-dimensional (2D) and three-dimensional (3D) ultrasound, magnetic resonance imaging (MRI), computed tomography (CT) scan and, finally, molecular diagnosis. The presence of craniosynostosis may affect the birthing process. Fetuses with craniosynostosis also have higher rates of perinatal complications. In order to avoid the risks of untreated craniosynostosis, children are usually treated surgically soon after postnatal diagnosis.
\end{abstract}

Keywords: craniosynostosis, Apert Syndrome, Pfeiffer Syndrome, Crouzon Syndrome, prenatal diagnosis

\section{Introduction}

Craniosynostosis is defined as the process of premature fusion of one or multiple cranial sutures. It is a common condition that occurs in about 1 to 2,000 live births [1]. Craniosynostosis may be classified in primary (caused by an intrinsic defect on the suture) or secondary (caused by other medical conditions, such as deficient brain growth) [1] and may also be classified as nonsyndromic (when it is isolated) or syndromic (when associated with other congenital anomalies) [2]. Premature closure of sagittal, bicoronal and metopic sutures is associated with dolichocephaly (or scaphocephaly), brach-

Received 07.01.2015 Accepted 19.02.2016

Med Ultrason

2016, Vol. 18, No 3, 378-385

Corresponding author: Prof. Edward Araujo Júnior, $\mathrm{PhD}$

Rua Belchior de Azevedo,

156 apto. 111 Torre Vitoria

São Paulo-SP, Brazil, CEP 05089-030

Phone/Fax: +55-11-37965944

E-mail: araujojred@terra.com.br ycephaly and trigonocephaly, respectively. When only one coronal or lambdoid suture is fused, plagiocephaly develops (ipsilateral forehead or occipital flattening). Cloverleaf and oxycephaly occur due to closure of multiple sutures [2]. Single-suture nonsyndromic synostosis comprises approximately $80 \%$ of craniosynostosis [3-5]. The frequency of the sutures involved is: sagittal, 40 to $58 \%$; coronal 20 to $29 \%$; metopic 4 to $10 \%$ and lambdoid 2 to $4 \%$ [1].

There is a wide range of syndromes involving craniosynostosis and the most common are Apert, Pffeifer, Crouzon, Shaethre-Chotzen, and Muenke syndromes [6]. Genotype/phenotype correlation, prenatal ultrasound clues, prognosis and treatment will be considered.

\section{Etiology and genetics}

The underlying etiology and potential risk factors of nonsyndromic craniosynostosis are unknown. Studies have shown association with positive family history and exposure to some medications, such as clomiphene cit- 
rate for infertility treatment [7], fluconazole [8], sodium valproate [9] and citalopram [10].

Positive family history, parental age, habits and use of teratogenic substances should also be accessed [5]. Genetic investigations have shown that mutations in the fibroblast growth factor (FGF) signalling pathway play a crucial role in the etiology of craniosynostosis syndromes. The FGF family of molecules regulate cell proliferation, differentiation and migration and act through the fibroblast growth factor receptors (FGFR). Gain-offunction mutations in FGFR1 and FGFR3 have been associated with syndromes related to craniosynostosis, as well as mutations in several transcription factors of the same pathway (e.g. loss-of-function due to mutation in TWIST1, which is thought to negatively regulate FGFR1) [1].

\section{Prenatal diagnosis}

Reports on prenatal ultrasound examination of cranial sutures are relatively rare in the literature [2,11-13] and the detection rates of craniosynostosis are low $[14,15]$. A retrospective study including 618 cases of isolated craniosynostosis revealed that only 2 cases $(0.3 \%)$ were known to have been diagnosed prenatally [16]. Although the majority of recent reports on prenatal diagnosis of suture fusion anomalies are related to syndromic cases [17-21], they contribute to detection of nonsyndromic craniosynostosis. Nowadays, different methods can be applied for prenatal diagnosis of craniosynostosis, such as two-dimensional (2D) and three-dimensional (3D) ultrasound, magnetic resonance imaging (MRI), computed tomography (CT) scan and, finally, molecular diagnosis. Further considerations will be made on this topic in the next section.

Prenatal ultrasound diagnosis, though difficult, should prompt diagnosis of craniosynostosis by visualization of indirect signs, such as abnormal cephalic index (CI), cranial shape and/or face morphology [22]. CI, which consists in the relationship between biparietal and occipto-frontal diameters, is considered normal from 75 to $85 \%$. Dolichocephaly is defined by a CI below $75 \%$ and brachycephaly by a CI above $85 \%$ [23]. Abnormal calvarium contour can also be found as unilateral cranial flattening, asymmetries or cloverleaf shaped skull. The brain parenchyma and the cerebral ventricles should also be evaluated as fetuses with craniosynostosis may exhibit enlarged cerebral ventricles [14]. Facial anomalies, especially in the size and shape of the orbits may be associated with craniosynostosis [3]. Hyper or hypotelorism may be related to craniosynostosis when the anterior coronal and frontal sutures are involved, respectively [22]. It is important to highlight that, in cases of isolated dolichocephaly or brachycephaly up to $80 \%$ may have a normal outcome [2]. The ultrasound diagnosis of craniosynostosis per se is made when there is a loss of hypoechogenicity in a segment of the normal skull sutures, which is usually associated with an enlargement of other orthogonal sutures [22]. However, in a retrospective study of fetuses at risk for craniosynostosis, dysmorphology and skull deformity preceded closure of the sutures by 4 to 16 weeks [2]. In a population at risk for this condition, the positive predictive value of direct examination of the sutures may be high, while in low-risk pregnancies it may be minimal, and further investigation may be necessary (3D ultrasound, CT scan or MRI) [2,20].

The most important consideration in the prenatal ultrasound assessment of craniosynostosis is the distinction between isolated and syndromic craniosynostosis. Therefore, it is extremely relevant to detail fetal anatomy as a whole. Special attention should be paid to fetal hands and feet, long bone growth, central nervous system and heart [3]. The evaluation of fetal head, face and sutures can be complemented by 3D ultrasound $[11,13,24]$. A report has shown that 3D ultrasound revealed diagnostic features of Apert syndrome, such as wide metopic suture and absent coronal sutures earlier than 2D ultrasound [25]. In addition, it was possible to measure metopic gap using 3D ultrasound in cases of Apert syndrome [26]. 3D ultrasound may also be useful in the evaluation of hand, feet and facial features, especially in syndromic cases $[27,28]$. Besides, it can improve parental counselling [29]. Reports on fetal magnetic resonance imaging (MRI) of craniosynostosis are rare in the literature; however MRI can be considered complimentary [30] to ultrasound and seems to have negative predictive value when synostosis is suspected on ultrasonography [15]. Cranial sutures cannot be visualized directly, but indirect signs such as skull deformities can be seen as temporal indentations ("notch at the level of coronal sutures") or thickening of the calvarium in the region of the suture [15]. Furthermore, brain abnormalities may be present and MRI can provide a good assessment of them [15,22,31]. Furthermore, MRI may also contributes, such 3D ultrasound, in the evaluation of hands and feet and differential diagnosis between syndromic craniosynostosis [32].

3D CT is another diagnostic investigation that allows direct examination of cranial sutures, bony anatomy of fetal face and skull base [15,33]. The disadvantage of such technique is the presence of fetal irradiation, although the theoretical exposure to radiation is very similar to that of conventional fetal radiological examination or pelvic CT scanning in pregnancy (3 mGy) [34]. 
Although prenatal ultrasound diagnosis of craniosynostosis is usually suspected in the second or third trimester, molecular diagnosis may rely on either chorionic villus sampling (particularly useful in case of recurrence) or amniocenteses or by preimplantation diagnosis [1] considering that fetal karyotype is usually normal [35]. Fluorescence in situ hybridization (FISH) and arraycomparative genomic hybridization (a-CGH) may be applied to fetal DNA [36].

Common craniosynostosis syndromes all show dominant inheritance but most cases are sporadic and result from de novo mutation or a genotype/phenotype correlation may not be demonstrated. For these reasons, genetic counselling can be challenging [37]. Recently, non-invasive prenatal diagnosis (NIPD) based on cellfree fetal DNA in maternal blood has been tested for antenatal, non-invasive diagnosis of single-gene disorders although some concerns have been raised (rarity of the condition and availability of suitable technical platforms) [38]. Enrichment of fetal mutated alleles in maternal plasma based on CO- amplification at lower denaturation temperature-PCR (COLD-PCR) has been used for NIPD of craniosynostosis. The method enabled correct identification of the paternally inherited mutated allele, in accordance with the result obtained on DNA extracted from chorionic villi [39].

\section{Differential diagnosis}

\section{Apert syndrome}

Apert syndrome (OMIM \#101200) is a rare condition characterized by a triad: craniosynostosis, midface hypoplasia and cutaneous and bony symmetrical syndactyly of hands and feet. The prevalence is around 1 in 65,000 newborns and it accounts for about $4.5 \%$ of all cases of craniosynostosis [35]. Two FGFR2 mutations (S252W and P253R) located on chromosome 10q26 are responsible for $98 \%$ of cases and a paternal age effect in de novo mutations has been shown [1]. A variety of malformations, particularly in central nervous system (CNS), can be associated with the syndrome. Cardiac and urogenital disorders are also frequently found. In 2D ultrasound evaluation, abnormal skull shape (turribrachycephaly - shorter and wider than normal skull, with compensatory vertical growth), facial abnormalities and the absence of distinct and separate movements of the fingers and toes ("mitten type" syndactyly) are the clues for the diagnosis $[3,40]$ (Fig. 1 and Fig. 2). In Apert syndrome there is bilateral fusion of the coronal sutures and a widened metopic suture, with sagittal suture extending from the glabella to the posterior fontanella, which can be well demonstrated by 3D ultrasound. This feature contributes to the differentiation with other syndromes characterized by acrocephaly in Crouzon syndrome while Carpenter syndromes results from synostosis of coronal, sagittal and lambdoid sutures and Pfeiffer syndrome closure of sagittal and coronal sutures [25]. Fetal MRI may be useful in the evaluation of associated intracranial conditions, such as vetriculomegaly, agenesis of corpus callosum (ACC) and abnormalities of the septum pellucidum, commonly seen in Apert syndrome [30]. Frontal lobe overexpansion (bulging of the surface of the temporal lobe beyond the contour of the adjacent frontoparietal lobe) and overconvolution have also been described by MRI and are associated with intellectual disability [18]. Fetal MRI has proved to be useful in the examination of the fetal face (beaked nose, hypertelorism) and palate (cleft palate) [18]. Nonetheless, fetal echocardiogram should be performed, given that cardiac malformations are also frequently associated with the syndrome [3]. In the presence of the above findings, genetic counselling is recommended and molecular prenatal diagnosis may be offered.

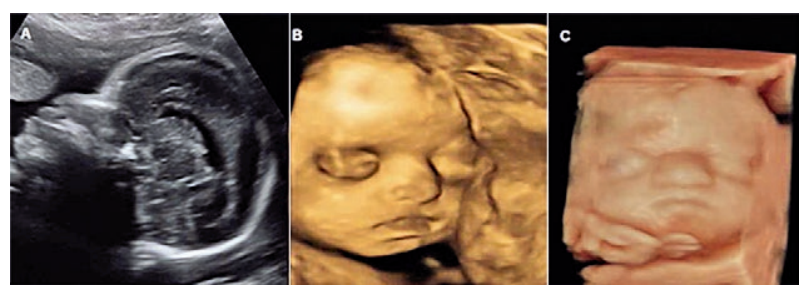

Fig 1. Apert syndrome findings in a fetus with $26 \mathrm{w} 6 \mathrm{~d}$ of gestation using 2D ultrasound (sagittal view) (A) and 3D ultrasound (rendering and HDlive modes, respectively) (B and C). Synostosis coronal, frontal bossing, wide metopic suture, nasal bridge depression, hypertelorism with proptosis bilateral and maxillary hypoplasia with relative prognathism.

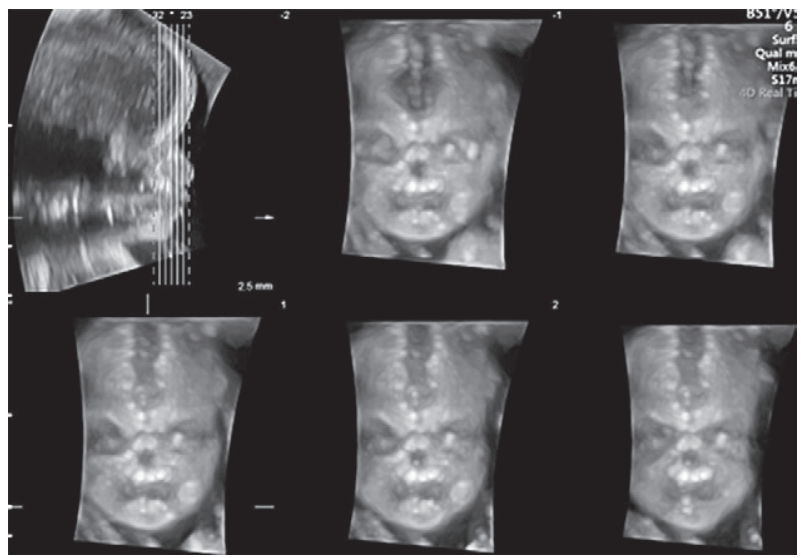

Fig 2. Apert syndrome findings in a fetus with $25 \mathrm{w} 1 \mathrm{~d}$ of gestation by $3 \mathrm{D}$ ultrasound using the software tomography ultrasound imaging (TUI). Synostosis coronal, frontal bossing, wide metopic suture, and nasal bridge depression. 


\section{Pfeiffer syndrome}

Pfeiffer syndrome (OMIM \#101600) is characterized by craniosynostosis (mostly involving coronal sutures), midface hypoplasia (and other facial features secondary to synostosis) and anomalies of hand and feet (broad thumbs and great toes deviated away from other digits) [41]. It affects about 1 in 100,000 individuals and three subtypes have been identified [42,43]. Type 1 is caused by heterozygous mutations in the FGFR1 gene located on chromosome 8p11.23 while type 2 and type 3 are due to mutation on FGFR2 located on 10q26.13, respectively. Prenatal ultrasound diagnosis of Pfeiffer syndrome has been reported. Abnormalities in skull shape (brachycephaly, acrocephaly, cloverleaf skull), face (small nose, low nasal bridge and bulging front) and hands/feet (broad thumb/big toe) are usually the main phenotypic features $[28,41]$. The presence of "big eyes" or proptosis and hypertelorism may be also relevant $[41,42]$. Polyhydramnios has been associated with Pfeiffer type 1 and type 2, and close monitoring of pregnancy should be performed in these cases $[32,44]$. Moreover, other visceral abnormalities may eventually be detected by $2 \mathrm{D}$ ultrasound. 3D ultrasound contributes to evaluation of coronal synostosis, fetal face and limbs [28]. Exophthalmos, for instance, can be better seen by 3D ultrasound [32].

While Pfeiffer syndrome type I is compatible with life and has a normal intellectual development, Pfeiffer syndrome type II and type III are associated with poor prognosis (early death or psychomotor and mental retardation in survival) [45], molecular diagnosis is fundamental for genetic counselling [46] and antenatal management. In surviving infants, improvement in intellectual development following cranioplasty has been reported in only one case [47]. Associated anomalies such as ventriculomegaly can be seen in all three types of Pfeiffer syndrome as well as choanal or laryngotracheal abnormalities, cleft palate, sacrococcygeal eversion/appendage and congenital heart disease may be present in types 2 and type $3[32,42]$.

\section{Crouzon syndrome}

Crouzon syndrome (OMIM \#123500) is an autosomal dominant (AD) disease caused by mutation in FGFR2 located on 10q26.13 and has an incidence in about 1: 25,000 live births [6]. If FGFR2 mutation is not found, a p.Ala391Glu FGFR3 mutation should be suspected and tested for a p.Ala391Glu FGFR3 mutation, responsible for Crouzon syndrome with acanthosis nigricans (CAN) [27]. Typical Crouzon phenotype includes brachycephaly, shallow orbits with proptosis, midface hypoplasia and anterior open bite (because of midface hypoplasia associated with normal mandibular growth). Commonly, no limb anomalies are associated with the condition [6,27]. Cranial synostosis is normally bilateral and involves the coronal su- ture with eventual pansynostosis; intellectual development is usually normal [1]. Crouzon syndrome can be suspected by $2 \mathrm{D}$ and $3 \mathrm{D}$ ultrasound by findings of brachycephaly, hypertelorism, ocular proptosis, and beaked nose. Prognosis is characterized by mental retardation, hearing loss and speech delay can be found in Crouzon syndrome [48].

\section{Saethre-Chotzen syndrome}

Saethre-Chotzen syndrome (OMIM \#101400) may recognize haploinsufficiency mutation in TWIST1 gene located on 7p21.11 chromosome or mutation in the FGFR2 located on chromosome 10q26.13 [36]. The syndrome has a birth prevalence of 1 per 50,000 to 1 per 25,000 and phenotype includes uni or bicoronal synostosis, facial asymmetry, low frontal hairline, hypertelorism, blepharoptosis, arched palate, small ears, brachydactyly, broad toes and cutaneous syndactyly or clinodactyly [36,40]. Prenatal 2D ultrasound diagnosis can be suspected by presence of brachycephaly, mid-face hypoplasia and limb defects although detection rate of ultrasound is poor [36,40]. Polyhydramnios and cardiac anomalies may be associated findings and fetal echocardiogram is recommended [49]. Intelligence is usually normal, although individuals with large genomic deletions are more likely to have developmental delays [50].

\section{Muenke syndrome}

Muenke syndrome (OMIM \#602849) is described as a P250R mutation in FGFR-3 on chromosome 4p16.3 with an incidence of 1 in 10,000 and an AD inheritance pattern with variable expressivity even within the same family [51]. It is estimated that Muenke syndrome may accounts for $10 \%$ of unilateral coronal or bilateral coronal synostosis cases that were previously believed to be nonsyndromic in origin [6]. Diagnostic clue of the disease is a thimble-like middle phalanges while midface hypoplasia is not a common [6]. Frontal bossing has been described at third trimester scan [52]. Strabismus is common as hearing loss $(33 \%-100 \%$ of affected individuals), developmental delay ( $\sim 33 \%)$, epilepsy, intracranial anomalies and intellectual disability.

\section{Treatment}

In order to avoid craniosynostosis related complications, children are usually treated surgically by a multispecialist team to unlock and reshape the cranial bones [4]. Surgical correction of craniosynostosis may not alter the mental retardation [53]. Acute care of newborn infants with severe multiple synostosis is directed towards maintenance of the upper airway, feeding support, eye protection, and treatment of raised intracranial pressure (ICP), when present. Raised ICP associated with craniosynostosis has several different causes, which require different treatments. Hydrocephalus needs shunt placement; ob- 
structive sleep apnea is treated by improving the airway. Craniocerebral disproportion (the consequence of craniosynotosis) requires calvarial expansion. Foramen magnum decompression might be required if there is tonsillar herniation. In multiple synostosis, abnormal venous drainage poses a significant hazard when operating on the back of the skull [40]. The need for secondary revision procedures is inversely related to the age of the affected individual at the time of initial repair. The location of the fused/synostotic suture, type of fixation, and the use of bone grafting do not have a significant effect on the need for revision [54].

Elective surgical treatment of craniosynostosis has three major objectives, which are correction of skull deformity, prevention of its progression and reduction of future risk to develop increased ICP. Depending on severity, the first craniosynostosis repair (fronto-orbital advancement and cranial vault remodeling) is typically performed between ages three and six months. An alternative approach is endoscopic strip craniectomy, which is a less invasive procedure and is typically performed prior to age three months [54].

\section{Prognosis}

The presence of craniosynostosis may affect the birthing process by increasing unplanned Cesarean delivery rate and birth trauma, probably due to cephalopelvic disproportion [14]. In addition, there is a significantly higher rate of malpresentations at birth (abnormal cephalic and breech presentations) [14,18]. An improvement in the prenatal diagnosis of these diseases could contribute to the reduction of maternal-fetal trauma [14].

Table I. Clinical findings of craniosynostisis syndromes.

\begin{tabular}{|c|c|c|c|c|}
\hline Syndromes & Incidence & Main Findings & Other Signs & $\begin{array}{l}\text { Intellectual } \\
\text { Development }\end{array}$ \\
\hline Apert & $1: 65,000$ & $\begin{array}{l}\text { Bicoronal synostosis, maxillary hypo- } \\
\text { plasia, flat, recessed forehead, flat midface, } \\
\text { exorbitism, hypertelorism, low-set ears , } \\
\text { abnormally small, flat nasal structure with } \\
\text { a bulbous tip, high arched palate, cleft } \\
\text { palate, maxillary dental arch V-shaped, } \\
\text { strabismus, syndactyly }\end{array}$ & $\begin{array}{l}\text { Malformation of the corpus callosum and } \\
\text { limbic structures, gyral abnormalities, } \\
\text { hypoplastic white matter, and heterotopic } \\
\text { gray matter, ventriculomegaly, cardiovas- } \\
\text { cular (atrial septal defect, ventricular septal } \\
\text { defect, patent foramen ovale, overriding } \\
\text { aorta) and genitourinary (hydronephrosis, } \\
\text { cryptorchidism) }\end{array}$ & $\begin{array}{l}\text { Normal to } \\
\text { mental defi- } \\
\text { ciency }\end{array}$ \\
\hline $\begin{array}{l}\text { Pfeiffer } \\
\text { Type I }\end{array}$ & 1: 100,000 & $\begin{array}{l}\text { Craniosynostosis, centro-facial hypoplasia, } \\
\text { broad thumbs, broad big toes, brachydactyly }\end{array}$ & Deafness hydrocephalus & $\begin{array}{l}\text { Normal } \\
\text { psychomotor } \\
\text { and mental }\end{array}$ \\
\hline Type II & & $\begin{array}{l}\text { Variable syndactyly, cloverleaf skull, } \\
\text { severe exophthalmia, broad thumbs, broad } \\
\text { big toes, brachydactyly, variable syndac- } \\
\text { tyly, ankylosis of the elbow }\end{array}$ & $\begin{array}{l}\text { Atresia or stenosis of the external auditory } \\
\text { canal, atresia or stenosis of the posterior } \\
\text { apertures of the nose, laryngotracheal } \\
\text { abnormalities, hydrocephalus, convulsion, } \\
\text { cerebral or cerebellar hernia, hydronephro- } \\
\text { sis, kidneys in pelvic position bifid scro- } \\
\text { tum, intestinal malrotation, malposition of } \\
\text { the anus, hypoplastic gall bladder }\end{array}$ & $\begin{array}{l}\text { Psychomotor } \\
\text { and mental } \\
\text { retardation }\end{array}$ \\
\hline Type III & & $\begin{array}{l}\text { Craniosynostosis, severe exophthalmia, } \\
\text { broad thumbs, broad big toes, brachydac- } \\
\text { tyly, variable syndactyly, ankylosis of the } \\
\text { elbow }\end{array}$ & $\begin{array}{l}\text { Atresia or stenosis of the posterior aper- } \\
\text { tures of the nose, laryngotracheal abnor- } \\
\text { malities, hydrocephalus, convulsion }\end{array}$ & \\
\hline Crouzon & $1: 25,000$ & $\begin{array}{l}\text { Tall, flattened forehead (secondary to } \\
\text { bicoronal synostosis), proptosis, a beaked } \\
\text { nose, and midface hypoplasia }\end{array}$ & Cleft palate, cervical spine abnormalities & $\begin{array}{l}\text { Normal most } \\
\text { of cases }\end{array}$ \\
\hline $\begin{array}{l}\text { Saethre- } \\
\text { Chotzen }\end{array}$ & $1: 50,000$ & $\begin{array}{l}\text { Craniosynostosis, } \\
\text { towering (turricephalic) forehead, low-set } \\
\text { hairline, facial asymmetry with septal } \\
\text { deviation, and ptosis of the upper eyelids, } \\
\text { syndactyly }\end{array}$ & $\begin{array}{l}\text { Polyhidramnios, } \\
\text { cardiac abnormalities }\end{array}$ & $\begin{array}{l}\text { Normal most } \\
\text { of cases }\end{array}$ \\
\hline Muenke & $1: 10,000$ & $\begin{array}{l}\text { Craniosynostosis, } \\
\text { hearing loss, and thimble-like middle } \\
\text { phalanges. Midface hypoplasia is not a } \\
\text { common finding }\end{array}$ & $\begin{array}{l}\text { Strabismus, epilepsy, intracranial abnor- } \\
\text { malities }\end{array}$ & $\begin{array}{l}\text { Develop- } \\
\text { mental delay } \\
(30 \%)\end{array}$ \\
\hline
\end{tabular}


Fetuses with craniosynostosis also have higher rates of perinatal complications, such as lower Apgar score and lower $\mathrm{pH}$ values as compared with control group [18]. After birth, untreated craniosynostosis may result in worsened cranial deformity, cranial growth restriction and increased intracranial pressure, as observed mainly in syndromic cases [4]. In a recent review, the majority of studies showed that children with craniosynostosis are at elevated risk for adverse neurodevelopmental functioning during infancy and early childhood [19].

Airway obstructions are observed in $40 \%$ of patients with severe craniosynostotic syndromes $[55,56]$. Obstruction may be secondary to midface hypoplasia or lower airway obstruction, tonsillar and adenoid hypertrophy, or choanal atresia. Airway obstruction may result in apnea and cor pulmonale and may require tracheostomy [57]. Mental delay or retardation may occur in approximately one-half of these cases [58]. The frequency of increased intracranial hypertension and the risk of mental impairment depend on the age of the child and the type of craniosynostosis [59]. Abnormalities of the extremities may be symptomatic. Foot and toe deformities may lead to foot problems and pain [60].

Table I summarizes the main findings of craniosynostosis syndromes.

\section{Conclusion}

Craniosynostosis is the premature fusion of one or more cranial sutures. Premature fusion restricts the growth of the skull perpendicular to the affected suture. Compensatory skull growth occurs parallel to the affected suture in order to accommodate the growing brain. Despite the great advancement in the molecular diagnosis of craniosynostosis, prenatal ultrasound still carries a low detection rate as genotype/phenotype correlations are frequently overlapping between these syndromes. Postnatal multispecialist surgery is essential in preventing intracranial hypertension, improving socialization by normalizing the appearance of the face and head.

\section{References}

1. Kimonis V, Gold JA, Hoffman TL, Panchal J, Boyadjiev SA. Genetics of craniosynostosis. Semin Pediatr Neurol 2007; 14: 150-61.

2. Delahaye S, Bernard JP, Rénier D, Ville Y. Prenatal ultrasound diagnosis of fetal craniosynostosis. Ultrasound Obstet Gynecol 2003; 21: 347-353.

3. Bianchi DW, Crombleholme TM, D'Alton ME, Malone FD. Fetolgy: Diagnosis and Management of the Fetal Patient. $2^{\text {nd }}$ ed. McGraw-Hill Companies; 2000.
4. Governale LS. Craniosynostosis. Pediatr Neurol 2015; 53 : 394-401.

5. Blaser SI, Padfield N, Chitayat D, Forrest CR. Skull base development and craniosynostosis. Pediatr Radiol 2015; 45 Suppl 3: 485-496.

6. Derderian C, Seaward J. Syndromic craniosynostosis. Semin Plast Surg 2012; 26: 64-75.

7. Ardalan M, Rafati A, Nejat F, Farazmand B, Majed M, El Khashab M. Risk factors associated with craniosynostosis: a case control study. Pediatr Neurosurg 2012; 48: 152-156.

8. Lopez-Rangel E, Van Allen MI. Prenatal exposure to fluconazole: an identifiable dysmorphic phenotype. Birth Defects Res A Clin Mol Teratol 2005; 73: 919-923.

9. Lajeunie E, Le Merrer M, Marchac D, Renier D. Syndromal and nonsyndromal primary trigonocephaly: analysis of a series of 237 patients. Am J Med Genet 1998; 75: 211215.

10. Durham E, Jen S, Wang L, et al. Effects of Citalopram on Sutural and Calvarial Cell Processes. PLoS One 2015; 10:e0139719.

11. Faro C, Benoit B, Wegrzyn P, Chaoui R, Nicolaides KH. Three-dimensional sonographic description of the fetal frontal bones and metopic suture. Ultrasound Obstet Gynecol 2005; 26: 618-621.

12. Patel MD, Swinford AE, Filly RA. Anatomic and sonographic features of the fetal skull. J Ultrasound Med 1994; 13: 251-257.

13. Pretorius DH, Nelson TR. Prenatal visualization of cranial sutures and fontanelles with three-dimensional ultrasonography. J Ultrasound Med 1994;13:871-876.

14. Miller C, Losken HW, Towbin R, et al. Ultrasound diagnosis of craniosynostosis. Cleft Palate Craniofac J 2002; 39: 73-80.

15. Fjørtoft MI, Sevely A, Boetto S, Kessler S, Sarramon MF, Rolland M. Prenatal diagnosis of craniosynostosis: value of MR imaging. Neuroradiology 2007; 49: 515-521.

16. Swanson J, Oppenheimer A, Al-Mufarrej F, et al. Maternofetal Trauma in Craniosynostosis. Plast Reconstr Surg 2015; 136: 214e-222e.

17. Chen CP, Su YN, Hsu CY, et al. Second-trimester molecular prenatal diagnosis of sporadic Apert syndrome following sonographic findings of mild ventriculomegaly and clenched hands mimicking trisomy 18 . Taiwan J Obstet Gynecol 2010; 49: 129-132.

18. Stark Z, McGillivray G, Sampson A, et al. Apert syndrome: temporal lobe abnormalities on fetal brain imaging. Prenat Diagn 2015; 35: 179-182.

19. Haye D, Collet C, Sembely-Taveau C, et al. Prenatal findings in carpenter syndrome and a novel mutation in RAB23. Am J Med Genet A 2014; 164A: 2926-2930.

20. Weber B, Schwabegger AH, Oberaigner W, Rumer-Moser A, Steiner H. Incidence of perinatal complications in children with premature craniosynostosis. J Perinat Med 2010; 38.

21. Knight SJ, Anderson VA, Spencer-Smith MM, Da Costa AC. Neurodevelopmental outcomes in infants and children 
with single-suture craniosynostosis: a systematic review. Dev Neuropsychol 2014; 39: 159-186.

22. Tonni G, Panteghini M, Rossi A, et al. Craniosynostosis: prenatal diagnosis by means of ultrasound and SSSE-MRI. Family series with report of neurodevelopmental outcome and review of the literature. Arch Gynecol Obstet 2011; 283: 909-916.

23. Roberto R, Pilu G, Jeanty P, Ghidini A, Hobbins JC. Prenatal Diagnosis of Congenital Anomalies. Appleton \& Lange, Norwalk; 1988.

24. Lam H, Lo T-KK, Lau E, Chin R, Tang L. The use of 2and 3-dimensional sonographic scans in the evaluation of cranial sutures: prenatal diagnosis of Apert syndrome. J Ultrasound Med 2006; 25: 148-1484.

25. Esser T, Rogalla P, Bamberg C, Kalache KD. Application of the three-dimensional maximum mode in prenatal diagnosis of Apert syndrome. Am J Obs Gynecol 2005;193:17431745.

26. Faro C, Chaoui R, Wegrzyn P, Levaillant JM, Benoit B, Nicolaides KH. Metopic suture in fetuses with Apert syndrome at 22-27 weeks of gestation. Ultrasound Obstet Gynecol 2006;27:28-33.

27. Nørgaard P, Hagen CP, Hove H, et al. Crouzon syndrome associated with acanthosis nigricans: prenatal $2 \mathrm{D}$ and $3 \mathrm{D}$ ultrasound findings and postnatal 3D CT findings. Acta Radiol short reports 2012;1:1-5.

28. Medina M, Cortes E, Eguiluz I, Barber MA. Three-dimensional features of Pfeiffer syndrome. Int J Gynaecol Obs 2009; 105: 266-267

29. David AL, Turnbull C, Scott R, et al. Diagnosis of Apert syndrome in the second-trimester using $2 \mathrm{D}$ and $3 \mathrm{D}$ ultrasound. Prenat Diagn 2007; 27: 629-632.

30. Giancotti A, D'Ambrosio V, De Filippis A, et al. Comparison of ultrasound and magnetic resonance imaging in the prenatal diagnosis of Apert syndrome: Report of a case. Child's Nerv Syst 2014; 30: 1445-1448.

31. Quintero-Rivera F, Robson CD, Reiss RE, et al. Apert syndrome: what prenatal radiographic findings should prompt its consideration? Prenat Diagn 2006; 26: 966-972.

32. Itoh S, Nojima M, Yoshida K. Usefulness of magnetic resonance imaging for accurate diagnosis of Pfeiffer syndrome type II in utero. Fetal Diagn Ther 2006; 21: 168-171.

33. Mahieu-Caputo D, Sonigo P, et al. Prenatal diagnosis of sporadic Apert syndrome: a sequential diagnostic approach combining three-dimensional computed tomography and molecular biology. Fetal Diagn Ther 2001; 16: 10-12.

34. Ruano R, Molho M, Roume J, Ville Y. Prenatal diagnosis of fetal skeletal dysplasias by combining two-dimensional and three-dimensional ultrasound and intrauterine threedimensional helical computer tomography. Ultrasound Obstet Gynecol 2004; 24: 134-140.

35. Athanasiadis AP, Zafrakas M, Polychronou P, et al. Apert syndrome: the current role of prenatal ultrasound and genetic analysis in diagnosis and counselling. Fetal Diagn Ther 2008; 24: 495-498.

36. Spaggiari E, Aboura A, Sinico M, et al. Prenatal diagnosis of a 7p15-p21 deletion encompassing the TWIST1 gene involved in Saethre-Chotzen syndrome. Eur J Med Genet 2012; 55: 498-501.

37. Wilkie AOM, Bochukova EG, Hansen RMS, et al. Clinical dividends from the molecular genetic diagnosis of craniosynostosis. Am J Med Genet A 2007; 143A: 1941-1949.

38. Lench N, Barrett A, Fielding S, et al. The clinical implementation of non-invasive prenatal diagnosis for singlegene disorders: challenges and progress made. Prenat Diagn 2013; 33:555-562.

39. Galbiati S, Stenirri S, Sbaiz L, et al. Identification of an 18 bp deletion in the TWIST1 gene by CO-amplification at lower denaturation temperature-PCR (COLD-PCR) for non-invasive prenatal diagnosis of craniosynostosis: first case report. Clin Chem Lab Med 2014; 52: 505-509.

40. Ferreira JC, Carter SM, Bernstein PS, et al. Second-trimester molecular prenatal diagnosis of sporadic Apert syndrome following suspicious ultrasound findings. Ultrasound Obstet Gynecol 1999; 14: 426-430.

41. Nazzaro A, Della Monica M, Lonardo F, et al. Prenatal ultrasound diagnosis of a case of Pfeiffer syndrome without cloverleaf skull and review of the literature. Prenat Diagn 2004; 24: 918-922.

42. Chen CP, Huang HK, Liu YP, Chern SR, Su JW, Wang W. Pfeiffer syndrome with FGFR2 W290C mutation perinatally presenting extreme proptosis. Taiwan J Obstet Gynecol 2013; 52: 607-610.

43. Cohen MM. Pfeiffer syndrome update, clinical subtypes, and guidelines for differential diagnosis. Am J Med Genet 1993; 45: 300-307.

44. Nieuwenhuyzen-De Boer GM, Hoogeboom AJM, Smit LS, Heydanus R, Eggink AJ. Pfeiffer syndrome: the importance of prenatal diagnosis. Eur J Obstet Gynecol Reprod Biol 2014; 181: 339-340.

45. Johnson D, Wilkie AO. Craniosynostosis. Eur J Hum Genet 2011; 19: 369-376.

46. Ben Hamouda H, Tlili Y, Ghanmi S, et al. Pfeiffer syndrome type II discovered perinatally: Report of an observation and review of the literature. Diagn Interv Imaging 2012; 93: 785-789.

47. Soekarman D, Fryns JP, vanden Berghe H. Pfeiffer acrocephalosyndactyly syndrome in mother and son with cloverleaf skull anomaly in the child. Genet Couns 1992; 3 : 217-220.

48. Arnaud-Lopez L, Fragoso R, Mantilla-Capacho J, et al. Crouzon with acanthosis nigricans: further delineation of the syndrome. Clin Genet 2007; 72: 405-410.

49. Massalska D, Bijok J, Kucińska-Chahwan A, et al. Prenatal diagnosis of craniosynostosis (compound Saethre-Chotzen syndrome phenotype) caused by a de novo complex chromosomal rearrangement $(1 ; 4 ; 7)$ with a microdeletion of $7 \mathrm{p} 21.3-7 \mathrm{p} 15.3$, including TWIST1 gene--a case report. Ginekol Pol 2014; 85: 541-544.

50. Saethre-Chotzen Syndrome. Gallagher ER, Ratisoontorn C, Cunningham ML. In: Pagon RA, Adam MP, Ardinger $\mathrm{HH}$, Wallace SE, Amemiya A, Bean LJH, Bird TD, Fong CT, Mefford HC, Smith RJH, Stephens K, editors. GeneRe- 
views ${ }^{\circledR}$ [Internet]. Seattle (WA): University of Washington, Seattle; 1993-2015, 2003 May 16 [updated 2012 Jun 14].

51. Shaw A, Petersen OB, Chitty LS. Prenatal diagnosis of craniosynostosis: sonographic features of Muenke syndrome. J Obstet Gynaecol 2011; 31:770-771.

52. Gebb J, Demasio K, Dar P. Prenatal sonographic diagnosis of familial Saethre-Chotzen syndrome. J Ultrasound Med 2011; 30: 420-422.

53. Grayhack JJ, Wedge JH. Anatomy and management of the leg and foot in Apert syndrome. Clin Plast Surg 1991; 18: 399-405.

54. Agochukwu NB, Doherty ES, Muenke M. In: Pagon RA, Adam MP, Ardinger HH, Wallace SE, Amemiya A, Bean LJH, Bird TD, Fong CT, Mefford HC, Smith RJH, Stephens K, editors. GeneReviews ${ }^{\circledR}$ [Internet]. Seattle (WA): University of Washington, Seattle; 1993-2015, 2006 May 10 [updated 2014 Jun 19].
55. Menashe Y, Ben Baruch G, Rabinovitch O, Shalev Y, Katzenlson MB, Shalev E. Exophthalmus-prenatal ultrasonic features for diagnosis of Crouzon syndrome. Prenat Diagn 1989; 9: 805-808.

56. Lo LJ, Chen YR. Airway obstruction in severe syndromic craniosynosrosis. Ann Plast Surg 1999; 43: 258-264.

57. Sculerati N, Gottlieb MD, Zimbler MS, Chibbaro PO, McCarthy JG. Airway management in children with major craniofacial anomalies. Laryngoscope1998; 108: 18061812.

58. Perkins JA, Sie KC, Milczuk H, Richardson MA. Airway management in children with craniofacial anomalies. Cleft Palate Craniofac J 1997; 34: 135-140.

59. Sarimski K. Cognitive functioning of young children with Apert's syndrome. Genet Couns 1997; 8: 317-322.

60. Renier 0, Lajeunie E, Arnaud E, Marchac D. Management of craniosynostoses. Childs Nerv Syst 2000; 16: 645-658. 